\title{
Discrimination of direction of line and the effect of stimulus alignment'
}

\author{
R. W. Sekuler, BROWN UNIVERSITY \\ Judy F. Rosenblith, HARVARD MEDICAL SCHOOL
}

\begin{abstract}
Studies of form discrimination have shown that children, rats, and octopus confuse figures which are leftright mirror-images more often than those which are up-down mirror-images. The generality of this finding was tested in an experiment with first grade children. When figures were presented side by side, as in other studies on children, earlier findings were confirmed. The differential difficulty of left-right and up-down mirror-image discriminations was reversed, however, when the figures were presented one above the other. Implications for theories of form discrimination were discussed.
\end{abstract}

\section{Problem}

Early accounts of form perception in children demonstrated that geometric forms are discriminated with difficulty when they are "mirror-images" of one another (Davidson, 1934, 1935; Hanfmann, 1933). A mirrorimage of a two dimensional figure is that produced by rotating it through $180^{\circ}$ about an axis in the plane of the figure (Sutherland, 1961). Recent work (Rosenblith, 1961, 1963; Rudel \& Teuber, 1963) has shown "up-down" mirror-images to be better discriminated than "leftright" mirror-images. E. g., stimuli such as $\bigsqcup \prod$ or $\Pi$ Uare less often confused than stimuli such as $]$ [ or [].Comparison figures were always presented laterally, raising the possibility that findings might be a function of alignment. Hence we are investigating the effect of lateral vs. longitudinal presentation on relative difficulty of the two types of mirror-image discriminations.

\section{Procedure}

From a distance of $8 \mathrm{ft}$ Ss viewed pairs of figures which were 9 in across. Black outline figures were rearprojected onto a translucent screen by identical 300-w slide projectors. One threw its image near the top, the other beneath it separated by 2 in. Two classes of figures, triangles and circles, were used with six different orientations (see Fig. 1). Each circle had a $20^{\circ}$ gap in its circumference giving it a characteristic orientation. Each triangle had an orientation, defined by the position of the apex angle, which corresponded to one of the circles.

Ss were tested with either triangles or circles. Each of the six stimulus orientations served as standard 4 times, appearing at top or bottom according to a fixed random order. The comparison stimuli were presented successively in either of two orders. S regulated these with a large response button which could control either of the projectors. Ss learned to use the response button to change comparison figures in 6 practice trials with figures different from those to be tested.

Instructions: You will now see pairs of triangles (circles). Each of the triangles points or faces in a certain direction. (Each of the circles has a small piece missing from its outside. Some have the piece missing from its top, some from its bottom, some from one side, some from the other, and from places in between.) Your job will be to get two triangles (circles) on the screen that both point or face in the same direction (have the pieces missing from the same place, that both point or face in the same direction). You can do this by using the button just as you've been doing for the practice figures.

Ss indicated verbally when they thought the figures on the screen were the same. They weregiven no feedback as to the correctness of their judgments. Twelve first graders from a Providence Public school were tested on circles and 14 on triangles. ${ }^{2}$
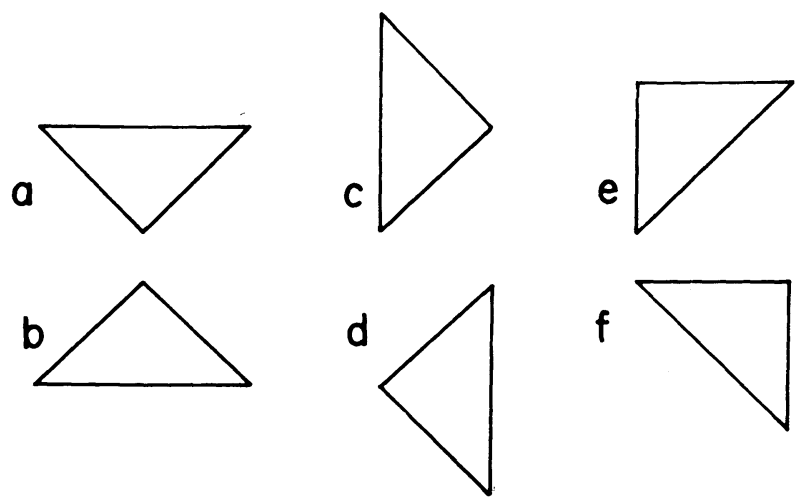

\section{Fig. Ib}

$a$<smiles>C1CCCCCCC1</smiles>

b

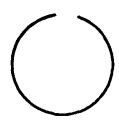

C

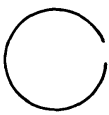

d

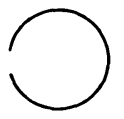

Fig. Ia
Fig. 1. 
Table 1. Number of Ss making errors of various types as a function of stimulus and mode of alignment.

\begin{tabular}{lrlllrlll} 
& \multicolumn{4}{c}{ Triangles } & \multicolumn{3}{c}{ Circles } \\
Type of & \multicolumn{4}{c}{ Alignment } & \multicolumn{3}{c}{ Alignment } \\
Error & Lateral & \multicolumn{1}{c}{ Longitudinal } & Lateral & Longitudinal \\
& & & & & & & & \\
Vertical & 0 & $(0)^{*}$ & 5 & $(11)$ & 0 & $(0)$ & 5 & $(14)$ \\
Horizontal & 10 & $(23)$ & 2 & $(3)$ & 11 & $(34)$ & 1 & $(1)$ \\
45 degree & 11 & $(22)$ & 4 & $(7)$ & 12 & $(34)$ & 0 & $(0)$ \\
Mixed & 2 & $(2)$ & 7 & $(27)$ & 4 & $(5)$ & 8 & $(26)$ \\
No-choice & 10 & $(22)$ & 8 & $(22)$ & 10 & $(30)$ & 5 & $(15)$
\end{tabular}

* Total number of errors in each cell is given in parenthesis.

\section{Hesults}

Errors were analyzed into five categories described with reference to the stimuli as labeled in Fig. 1 . When $a$ and $b$ are called the same, it is a vertical error; when $\mathrm{c}$ and $\mathrm{d}$ are, it is a horizontal error; when $\mathrm{e}$ and $\mathrm{f}$ are, it is a $45^{\circ}$ error. When a member of one pair is called the same as any from the other pairs (e.g., $\mathrm{a}=\mathrm{c}$ ), it is a "mixed error;" and when all six comparison stimuli are seen and none has been called the same as the standard, it is a "no-choice error."

These data, from stimuli presented one above the other (longitudinal alignment), may be compared with those from Ss tested the previous year with lateral alignment. Ss were from the same grade of the same school, and did not differ in CA or IQ. Apparatus, figures and instructions had been the same. The number of Ss making one or more errors in each of the five error categories is shown as a function of stimulus class and alignment in Table 1. Fisher's exact probability test was used to assess the effect of stimulus alignment on the number of Ss making an error for each stimulus class and error category. For both triangles and circles the effect of alignment was significant at the .05 level for horizontal, $45^{\circ}$, and vertical errors. Differences between alignments for mixed and no-choice errors were not significant for either class of stimuli. Ss made no vertical errors when figures were aligned laterally, but tended to make such errors when alignment was longitudinal. Both horizontal and $45^{\circ}$ errors were more frequent with lateral alignment than longitudinal.

\section{Discussion and Summary}

The present results suggest that when children compare figures in various orientations, the nature of the errors depends upon the alignment of the stimuli. Longitudinal alignment of standard and comparison figures increases vertical mirror-image errors; lateral alignment increases the likelihood that Ss will confuse stimuli which are left-right mirror-images. Up-down mirrorimage discrimination thus is not always easier than left-right. The relative difficulties depend upon the way in which the figures are aligned when shown to Ss.

Discriminations between up-down mirror-images are more easily learned by the rat (Lashley, 1938, simultaneous discrimination), and by the octopus (Sutherland, 1961, successive discriminations), than those between left-right mirror-images. The similarities between findings on octopus and children are striking. They have led to cautious speculation that similar mechanisms might mediate form discriminations in both species or that similarities may have arisen in response to similar environmental pressures (Rudel \& Teuber, 1963). Our data suggest that the similarity may be a function of the way in which standard and comparison figures have been aligned, and that the similarity breaks down when the alignment is longitudinal rather than lateral. Important determinants of form discrimination may as yet be unexplored. Concern with a theory of form perception and the mechanisms underlying it must await further investigation of such basic variables as the spatial relationships between standard and comparison stimuli.

\section{References}

DAVIDSON, HELEN P. A study of reversals in young children. J. genet. Psychol., 1934, 45, 452-465.

DAVIDSON, HELEN P. A study of the confusing letters b, d, p, and q. J. genet. Psychol., 1935, 47, 458-468.

HANFMANN, EUGENIA. Some experiments on spacial position as a factor in children's perception and reproduction of simple figures. Psychol. Forsch., 1933, 17, 319-329.

LASHLEY, K. S. The mechanism of vision: XV. Preliminary studies of the rat's capacity for detail vision. J. gen. Psychol., 1938, 18, 123-193.

ROSENBLITH, JUDY F. Perceptual discrimination in children. 1961 meetings of Society for Research in Child Development.

ROSENBLITH, JUDY F. Perceptual discrimination in children II. 1963 meetings of Society for Research in Child Development.

RUDEL, RITA, \& TEUBER, H. L. Discrimination of direction of line in children. J. comp. physiol. Psychol., 1963, 56, 892-898.

SUTHERLAND, N. S. Shape discrimination by animals. Experimental Psychology Society Monograph No. 1, 1961.

Notes

1. The writers thank Miss Evelyn Stern for her assistance. The investigation was supported in part by USPHS Grant B-3119 to Judy F. Rosenblith. We are indebted to Mr. John Brown, Principal in the Providence Public Schools for his cooperation.

2. Fifteen Ss for each stimulus set were intended, but an apparatus failure made it impossible to complete the data collection. 